who find the style off-putting should persevere, because Angier's gift for metaphor lights up the dustiest corners. Her explanation of how electromagnetic radiation is produced is superbly easy to visualize; she is lucid on evolution, and on intelligent design; and her chapter on molecular biology is an exemplary introduction. Science teachers should find numerous useful resources here. Instead of relying on geeks-and-gimmicks clichés - eccentric geniuses, bitter feuds and zany facts Angier's word-painting allows the scientific material to speak for itself in some depth. Consequently, we get a real sense of science as an immense collective endeavour, comprising both established knowledge and worksin-progress, done but not entirely dominated by personalities.

This is not a cutting-edge specialist text, so its contents are likely to be familiar to Nature readers. Much is necessarily omitted; the chapter on astronomy in particular feels disappointingly slight. Nevertheless, as an introductory guide, The Canon sets the standard for science writing and deserves at least to be shortlisted for the Royal Society Prize for Science Books. Its style may seem densely, even formidably, allusive at times, but Angier's gift for accessible explanation is outstanding. If any book can help the public learn to love science, this is it. Kathleen Taylor is in the Department of Physiology, Anatomy and Genetics, Oxford University, Parks Road, Oxford OX13PT, UK.

\section{The dark heart of the bomb}

\section{Plutonium: A History of the World's Most \\ Dangerous Element \\ by Jeremy Bernstein \\ Joseph Henry Press: 2007. 258 pp. \\ $\notin 16.99, \$ 27.95$}

\section{John S. Rigden}

Plutonium has either a celebrated or a tragic history, depending on your point of view. It was the core of the weapon that destroyed much of Nagasaki on 9 August 1945, and has only military uses. For those who find security standing behind a stockpile of plutonium bombs, the element is a reason to celebrate. By contrast, for those who regard the bombing of Nagasaki as a needless repetition of the Hiroshima catastrophe, plutonium is a symbol of the US-Soviet arms race that dominated the second half of the twentieth century. It now signifies the rank and status of a nation's military prowess.

In his book Plutonium, Jeremy Bernstein acknowledges that everything connected with the element is complicated, and that includes plutonium itself and its history. Its discovery in 1941 by Glenn Seaborg and Arthur Wahl is part of a much bigger story in which each part becomes a story in itself.

Plutonium does not occur in earthen deposits, for example; it is produced instead by the radioactive decay of uranium by way of neptunium, and it is with uranium that the book begins. Then there is the story of the periodic table and the problems associated with fitting the elements into their proper places especially the lanthanides (the elements of atomic number 58 to 71 that follow lanthanum in the periodic table) and the actinides (elements 90 to 103 following actinium). There is the story of radioactivity (and the connected story of the discovery of X-rays) and of Enrico
Fermi bombarding uranium nuclei with slow neutrons. Add to these the story of fission, with various elements and isotopes complicating the plot. Los Alamos and the development of atomic bombs are also a central part of the plutonium story. Finally, there are the complications arising from the element plutonium itself that must be understood and the associated problems solved. Melding these many parts into a short book represents a daunting challenge, which Bernstein confronts head on.

One of the benefits of this multifaceted approach is the opportunity it gives the author to educate readers by means of historical information and thumbnail sketches of interesting people. In his 1903 Nobel address, for example, Henri Becquerel, who discovered radioactivity, suggested that the energy associated with radioactivity may involve the modification of atoms in the radioactive material. Two years later, Einstein showed that there was a loss of mass, which becomes energy according to his famous equation $E=m c^{2}$. In 1934, Ida Noddack correctly criticized Fermi, suggesting that in his neutron-bombardment experiments he had actually discovered nuclear fission. Fermi's Nobel speech in 1938 was wrong on this point because he assumed he had discovered transuranic elements. When the Nobel Prize was awarded for the discovery of fission, the Nobel committee made so many erroneous assumptions about who did what, and when, that 